\title{
Structure and influence of tropical river plumes in the Great Barrier Reef: application and performance of an airborne sea surface salinity mapping system
}

\author{
D.M. Burrage ${ }^{\mathrm{a}, *}$, M.L. Heron ${ }^{\mathrm{b}}$, J.M. Hacker ${ }^{\mathrm{c}}$, J.L. Miller ${ }^{\mathrm{d}}$, T.C. Stieglitz ${ }^{\mathrm{a}}$, \\ C.R. Steinberg ${ }^{\mathrm{a}}$, A. Prytz \\ a Australian Institute of Marine Science, Townsville, Queensland 4810, Australia \\ ${ }^{\mathrm{b}}$ School of Mathematical and Physical Sciences, James Cook University, Queensland 4811, Australia \\ c Airborne Research Australia, Flinders University, Salisbury South, Adelaide, South Australia 5106, Australia \\ ${ }^{d}$ Ocean Sciences Branch, Naval Research Laboratory, Stennis Space Center, Hattiesburg, MS 39529, USA
}

Received 29 August 2002; received in revised form 27 November 2002; accepted 2 December 2002

\begin{abstract}
Input of freshwater from rivers is a critical consideration in the study and management of coral and seagrass ecosystems in tropical regions. Low salinity water can transport natural and manmade river-borne contaminants into the sea, and can directly stress marine ecosystems that are adapted to higher salinity levels. An efficient method of mapping surface salinity distribution over large ocean areas is required to address such environmental issues. We describe here an investigation of the utility of airborne remote sensing of sea surface salinity using an L-band passive microwave radiometer. The study combined aircraft overflights of the scanning low frequency microwave radiometer (SLFMR) with shipboard and in situ instrument deployments to map surface and subsurface salinity distributions, respectively, in the Great Barrier Reef Lagoon. The goals of the investigation were (a) to assess the performance of the airborne salinity mapper; (b) to use the maps and in situ data to develop an integrated description of the structure and zone of influence of a river plume under prevailing monsoon weather conditions; and (c) to determine the extent to which the sea surface salinity distribution expressed the subsurface structure. The SLFMR was found to have sufficient precision (1 psu) and accuracy ( $\sim 3 \mathrm{psu})$ to provide a useful description of plumes emanating from estuaries of moderate discharge levels with a salinity range of 16 to $32 \mathrm{psu}$ in the open sea. The aircraft surveys provided a means of rapidly assessing the spatial extent of the surface salinity distribution of the plume, while in situ data revealed subsurface structure detail and provided essential validation data for the SLFMR. The combined approach allowed us to efficiently determine the structure and zone of influence of the plume, and demonstrated the utility of sea surface salinity remote sensing for studying coastal circulation in tropical seas. (C) 2003 Published by Elsevier Science Inc.
\end{abstract}

Keywords: Great Barrier Reef; Sea surface salinity mapping system; Scanning low frequency microwave radiometer

\section{Introduction and background}

Salinity plays a vital role in the dynamics of coastal and marginal seas. Until recently, surface salinity observations could only be made by analyzing water bottle samples or conductivity, temperature, and depth (CTD) profiles obtained from in situ platforms and relatively slow moving

* Corresponding author. Present address: Department of Marine Science, University of Southern Mississippi, 1020 Balch Boulevard, Stennis Space Center, Hattiesburg, MS 39529, USA. Tel.: +1-228-6885241; fax: +1-228-688-5997.

E-mail address: Derek.Burrage@usm.edu (D.M. Burrage). vessels. The recent development of a capability to map sea surface salinity remotely, using light aircraft, provides a significant advance in the speed and resolution, both temporal and spatial, with which salinity distributions can be observed. We describe here the first attempt to use an airborne salinity sensor to map river plumes within the Australian coastal zone. The scanning low frequency microwave radiometer (SLFMR) used was constructed for an Australian research consortium by Quadrant Engineering (now ProSensing) of Amherst, MA, USA. Our use of this new instrument builds upon previous US coastal mapping experience, which employed the prototype SLFMR (Goodberlet, Swift, Kiley, Miller, \& Zaitzeff, 1997; Miller, 2000; Miller, Goodberlet, \& Zaitzeff, 1998). 
Early investigations of the relationship between ocean surface microwave emission and salinity were carried out by Sirounian (1968) and Paris (1969), while the crucial empirical relationships for the dielectric constant of seawater were precisely determined by Klein and Swift (1977). Successful airborne radiometer transects were obtained over the Mississippi outfall by Droppleman and Mennella (1970) and Thomann (1973), and more sensitive systems were flown over Chesapeake Bay by Blume, Kendall, and Fedors (1978) and Blume and Kendell (1982). The operating principles of various passive microwave radiometers, such as the Dicke Pulsed Noise Injection Radiometer design used in the SLFMR, are described by Dicke (1946), Hardy, Gray, and Love (1974), Ulaby, Moore, and Fung (1981), and Skou (1989).

Relatively precise and accurate 2-D mapping of sea surface salinity in coastal and open ocean regions has only recently become practical (Lagerloef, Swift, \& Le Vine, 1995). During the early 1990s, the University of Massachusetts Microwave Remote Sensing Laboratory and Quadrant Engineering, in collaboration with NASA Goddard Space Flight Center and NOAA, developed and tested two new multibeam imaging instruments for remotely mapping surface conductivity. While the electronically scanned thinned array radiometer (ESTAR) (Le Vine, Griffis, Swift, \& Jackson, 1994) was primarily designed to map soil moisture, it was successfully used by Le Vine, Kao, Garvine, and Sanders (1998) to map the Delaware Coastal Current from a NASA P-3 aircraft.

The scanning low frequency microwave radiometer, SLFMR (Goodberlet \& Swift, 1993), which is optimized to observe sea surface salinity, has been used to map salinity from a DeHavilland Beaver aircraft flying over US east and south coast estuaries and coastal waters (Goodberlet et al., 1997; Miller, 2000; Miller et al., 1998), and more recently from a twin-engined Piper Navajo aircraft. The design of the SLFMR is described by Goodberlet and Swift (1993), and a functional simulation of the instrument is presented by Burrage, Goodberlet, and Heron (2002). While it is conceptually similar to ESTAR and has the same antenna aperture, it is lighter and less bulky. Recent advancements include the development of a more sensitive version of the SLFMR called STARRS for the US Navy, provision of more accurate and precise aircraft navigation data, and addition of sensors to map surface roughness, which also affects instrument response.

ESTAR, SLFMR, and STARRS are all interferometers, but they differ in the manner in which the beams are formed and sampled. Thus, they sense the amplitude and phase of signals originating at the surface and arriving at an array of dipoles separated at fractional increments of a wavelength along a baseline. In SLFMR and STARRS, the beams are formed entirely in hardware using a passive Butler matrix (Skolnik, 1970). This transforms the signals received at the dipoles using appropriate phase shifts that account for the propagation path delays between the ocean surface and each dipole. The beams thus formed provide a measure of brightness temperature from each individual footprint on the sea surface. In contrast, ESTAR uses a combination of hardware correlators, rapid sampling, and post-processing software to form the beams, in the manner of many astronomical interferometers (LeVine et al., 1994). In the ESTAR design, the array is 'thinned' by removing dipoles that form redundant baseline pairs, whereas STARRS and SLFMR use a 'fully filled' eight-dipole array. Finally, the SLFMR samples the beam outputs from the Butler matrix sequentially, in a flyback scanning mode at intervals of approximately $4 \mathrm{~s}$, while STARRS samples all beams simultaneously, at intervals of about $0.5 \mathrm{~s}$ in a push-broom mode. In both STARRS and SLFMR, the dwell time for each beam sample is programmable, but is typically $0.5 \mathrm{~s}$. All three instruments use a 2-D dipole array with an aperture size of approximately $1 \mathrm{~m}$ to form a multibeam fan pattern in the across-track direction and a nadir-viewing single beam in the along-track direction. Half-power beam widths are approximately $15^{\circ}$ in both the along- and across-track directions, but the ESTAR nadir-viewing beam width is about half as wide.

We describe here a river plume mapping experiment in which intensive surface and subsurface sampling from in situ moorings and shipboard operations were combined with aircraft overflights of the Australian SLFMR. Horizontal profiles of temperature and salinity, and time series of current velocity, temperature, and depth, were obtained both within and outside the plume of the Herbert and Tully River in the vicinity of Hinchinbrook Island and Rockingham Bay, North Queensland (Fig. 1). The experiment was preceded by heavy rainfall in the river catchments due to tropical storms. This produced a strong discharge of freshwater (Fig. 2a) and consequent flooding in the estuary, a few days prior to our first airborne survey. During the ensuing 2-week period of fine weather, we mapped the temporal and spatial evolution of the plume as the river flow gradually subsided. Subsequently, two tropical cyclones (hurricanes in US terminology, henceforth TCs) approached the coast causing further flooding. These events were captured by the in situ instrumentation, which remained in place after the mapping experiment ended.

While the basic technology and hardware for L-band passive microwave remote sensing is quite advanced and well documented, obtaining the requisite instrumental precision and accuracy and refinement of the environmental correction algorithms are still critical issues in the use of the technique to remotely map sea surface salinity. Application of the technology to map soil moisture is at a similar developmental stage. However, the brightness temperature fluctuations that result from observed natural variations are significantly larger for soil moisture than they are for sea surface salinity; the soil moisture application is thus less demanding of high instrumental precision and accuracy (Lagerloef et al, 1995). While there is a substantial literature on single beam L-band microwave radiometer design and 


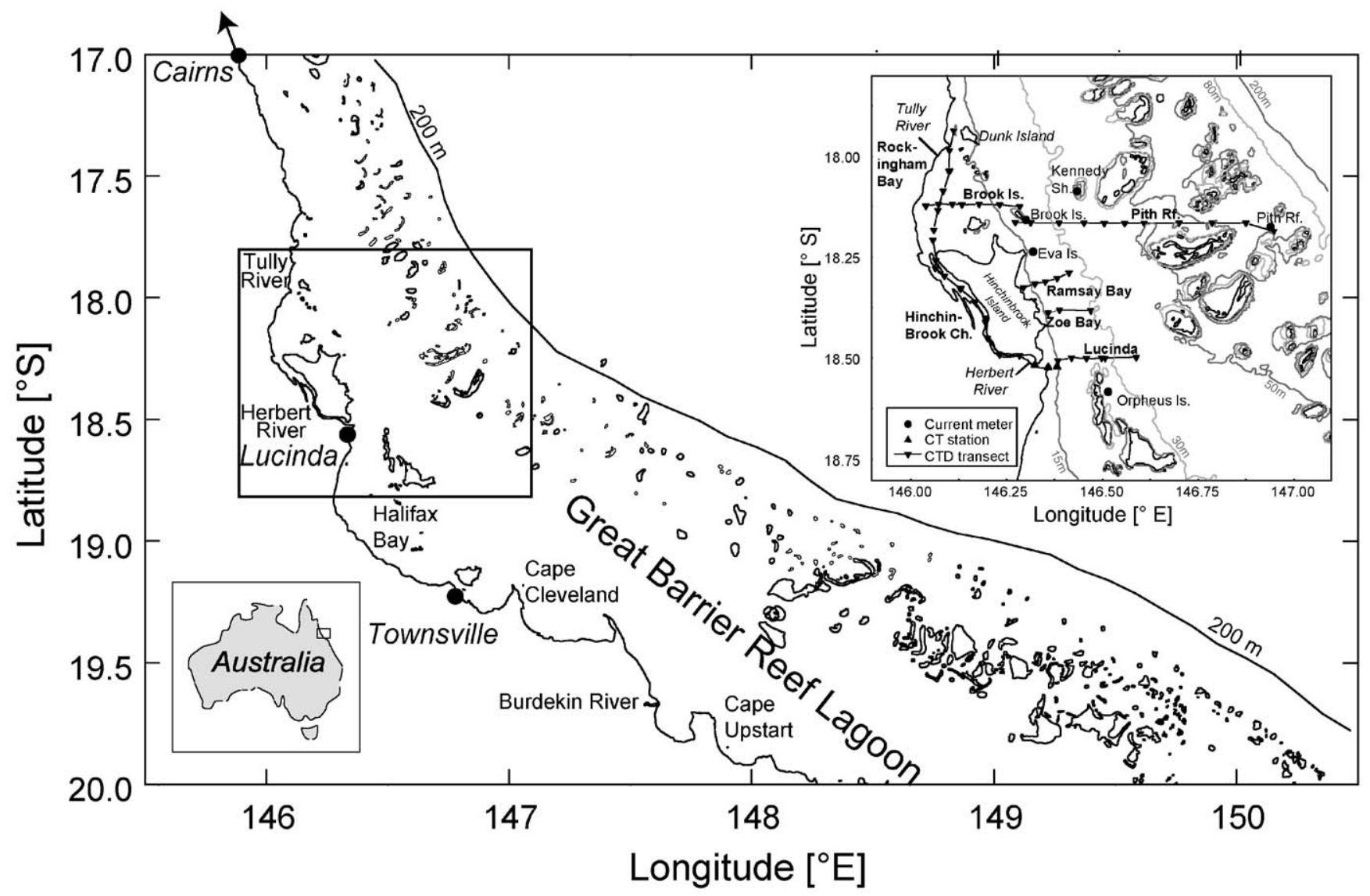

Fig. 1. Location of study area in northeastern Australia showing Great Barrier Reef and Lagoon inside the 200-m isobath. A map showing locations of in situ oceanographic moorings and CTD transects in the vicinity of Hinchinbrook Island is inset (top right). Transect labels indicate figures containing corresponding contour plots. The Eva Island and Pith Reef Current meters were ADCPs. Remaining current meters were S4s.

development (cited above), multibeam imagers are a relatively new innovation. Consequently, there have been relatively few practical demonstrations of these instruments that involve large-scale surveys and sea surface ground-truth data. None that we are aware of have purposely investigated the correspondence between airborne sea surface salinity
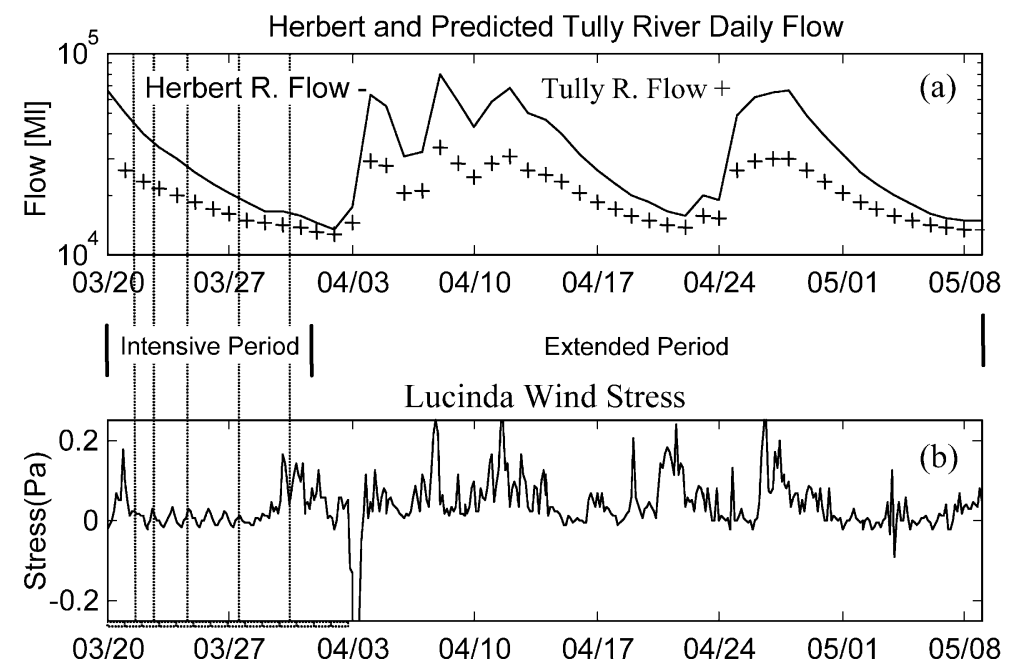

Fig. 2. Time series of river flow and wind stress for the experimental period. (a) Daily river flow (M1) for the Herbert River (observed) and Tully River (predicted). (b) Along-shelf wind stress (Pa) at Lucinda jetty. Daily tic marks appear at left in (b) and vertical lines mark times of salinity mapping flights during the intensive experimental period (March 27-30). Relatively calm dry conditions prevailed during this period which was bracketed by strong winds and high discharge, associated with storms, particularly in the extended period (March 31 -May 8). 
mapping data and subsurface salinity structure. In this paper, we briefly discuss the basic hardware design and operating principles. We then focus on the application and overall operational performance of the salinity mapping system in an oceanographic context in which the salinity distribution has a distinctly 3-D character. In this application, the synoptic surface salinity distribution observed using the salinity mapper is the key to interpreting and extrapolating the in situ information, and it provides a unique perspective on the evolution and potential impact of the observed salinity structure on the ecologically sensitive Great Barrier Reef World Heritage area. Further details of the oceanographic data processing and a dynamical interpretation of the observed river plume features are given in a companion paper (Burrage et al., 2002, in press, henceforth cited as BHSP2).

\section{Data acquisition and processing}

\subsection{Airborne salinity mapper}

\subsubsection{Specifications}

The airborne mapping instrumentation used was the SLFMR built by Quadrant Engineering (Goodberlet, 2000a, 2000b, 2000c). This is a pulsed noise injection Dicke radiometer that operates in the $1.4-\mathrm{GHz}(21-\mathrm{cm}$ wavelength) band. This band is utilized for astronomical hydrogen line spectrum observations and is protected from radio frequency interference by international agreement. The instrument passively observes the brightness temperature of the sea surface emission at this frequency. The emission is a known function of conductivity and hence of surface temperature and salinity (Klein \& Swift,1977). The radiometer uses a vertically polarized antenna system, consisting of an $8 \times 8$ element dipole array and a Butler beamforming matrix, to synthesize eight beams aligned acrosstrack at nominal incidence angles of $\pm 8^{\circ}, \pm 22^{\circ}, \pm 37^{\circ}$, and $\pm 61^{\circ}$ away from the nadir. Only data from the six inboard beams are used because the two outboard beams exhibit poor side-lobe response.

The nominal beam width of $15^{\circ}$ produces a footprint about $0.7-\mathrm{km}$ diameter, depending upon the beam incidence angle, at typical flight altitudes of $2000 \mathrm{~m}$. The aircraft altitude and speed are usually optimized to juxtapose or slightly overlap the beam footprints in the along-track direction for full coverage. The beams are sampled sequentially from left to right in a flyback scanning mode (Goodberlet \& Swift, 1993) by a single microwave receiver with a programmable dwell interval per beam set typically to $0.5 \mathrm{~s}$. A scan is thus completed in approximately $4 \mathrm{~s}$.

Specifications of the prototype SLFMR are given by Goodberlet and Swift (1993), while Goodberlet (2000a) presents the specifications of the Australian unit. The most important performance parameter for our purposes is Noise Equivalent Delta T (NEDT), which indicates the radiometric resolution or sensitivity of the instrument. Taking into account the receiver noise temperature, antenna losses, band width (24 MHz), and averaging time equivalent to the dwell time (Ulaby et al., 1981), the NEDT is estimated to be $0.5 \mathrm{~K}$. This translates into a salinity precision of approximately 1 psu (Klein \& Swift, 1977). Once calibrated, the absolute accuracy of the instrument is expected to be of the same order as the precision. In practice, we determined the accuracy empirically using in situ observations and found that the calibration with respect to ground-truth data drifted over a range of 3 psu during the course of the 10-day experiment.

\subsubsection{Temperature corrections}

The salinity mapper responds to variations in target brightness temperature associated with changes in microwave emissivity and the physical temperature of the sea surface. The emissivity depends upon the sea surface dielectric constant, which to first order is a function of both the physical temperature and salinity of the surface. Consequently, corrections for the target physical temperature must be made in the salinity retrieval algorithm. Surface roughness variations can also influence the response, but with the exception of our first and last flights, seas were relatively calm, so roughness influences likely had little impact. Neither clouds nor light rain significantly affect the transmission of L-band microwave radiation under typical SLFMR operating conditions.

Sea surface temperatures were remotely sensed using a Heimann infrared radiometer mounted in, and looking directly down from, an instrument bay in the aircraft nose. In contrast to the L-band measurements, those in the infrared band are generally affected by clouds which completely or partially obscure the radiometer's view of the sea surface. However, the weather was relatively clear during most of our flights, so little cloud contamination was experienced. The instrument has a beam width of $4^{\circ}$ and operates in the $8-14 \mu \mathrm{m}$ range (far infrared). In this range, the effective depth of emission or 'skin depth' is of the order of $10 \mu \mathrm{m}$. In general, the surface 'skin' temperature can differ by as much as $0.5{ }^{\circ} \mathrm{C}$ from that of subsurface waters. For the Heimann radiometer, the manufacturer's calibration was used. Based on cross-validation with other instruments (Airborne Research Australia, unpublished data), the accuracy is considered better than $0.5{ }^{\circ} \mathrm{C}$ and nominal precision is better than $0.2{ }^{\circ} \mathrm{C}$. Surface temperatures were verified using in situ data from selected CTD transects. At tropical summer seawater temperatures, the SLFMR salinity retrieval algorithm is relatively insensitive to temperature, so only modest accuracy and precision are required to correct the microwave radiometer brightness temperatures for the effects of physical target temperature variations. The available data are quite adequate for this purpose.

For microwave emission at $1.43 \mathrm{GHz}$, in the L-band, the skin depth is of order $5 \mathrm{~cm}$. At typical ocean temperatures of $20{ }^{\circ} \mathrm{C}$, it varies from about $1 \mathrm{~cm}$ for 35 -psu seawater through $2 \mathrm{~cm}$ at $10 \mathrm{psu}$ to $10 \mathrm{~cm}$ for freshwater (Swift, 1980). This confines our view to a thin surface layer that is 
likely mixed thoroughly by even modest surface wave action. The much smaller IR radiometer skin depth, of order $10 \mu \mathrm{m}$, confines the airborne temperature measurements to a thin surface boundary layer. Consequently, a physical temperature bias of order $0.5^{\circ} \mathrm{C}$ may be present when estimating seawater temperatures for use in the microwave radiometer salinity retrieval algorithm. However, this bias is not considered significant in our case due to the relative insensitivity of the emissivity to sea surface temperature in the tropics. For the same reason, possible temperature biases due to absorption of the infrared radiation by atmospheric water vapor were also considered negligible; so, no allowance was made for that effect.

\subsubsection{Logistics}

The SLFMR was mounted beneath the fuselage of the twin-engined Cessna 404 operated by Airborne Research Australia (ARA), and real-time processing hardware was mounted in equipment racks in the cabin. Both GPS and inertial navigation systems were employed. Aircraft attitude (pitch and roll) was provided by a precise differential GPS system (Trimble TANS Vector) that uses wing and fuselagemounted antennae. Accurate and precise navigation is essential not only for positioning, but also for applying appropriate angular corrections to the SLFMR data and for providing accurate geo-referencing. The TANS system mounted on the Cessna 404 has an angular accuracy of approximately $0.1^{\circ}$ and a positional accuracy of about $6 \mathrm{~m}$.

Flight times, altitudes, and track orientation were planned to minimize the effects of sun glint and reflected galactic emissions and to effectively resolve plume structure and extent. We also flew under stratiform cumulus cloud cover when present, because of visual flight rule restrictions, and to avoid loss of infrared radiometer sea surface temperature data. Five of the seven overflights performed included mountainous Hinchinbrook Island in the domain (Fig. 1). These five were made in the afternoons of March 21/22, 24, 27, and 30 in year 2000 (Table 1). The other two flights were made at night on March 22 and 23 to extend the domain southward to include Halifax Bay and Cape Cleveland (Fig. 1). The flights were all performed after 3 PM Australian Eastern Standard Time (EST). The aircraft tracks were aligned approximately across shelf for the first two (juxtaposed) flights (Fig. 3a) and along shelf for the last three flights (Fig. $3 b-d$ ), rather than E-W, in order to minimize glint from the setting sun. Resolution was further enhanced over the plume source at the south end of the island by flying lower and with an across-shelf orientation.

The Halifax flights (Table 1) were all done at an altitude of about $3000 \mathrm{~m}$. For the Hinchinbrook Island flights (Table 1), the NE-SW traverses at the southern end of the domain were done at an altitude of $1000 \mathrm{~m}$. We ascended to $1500 \mathrm{~m}$ for the NW-SE traverses along the island. The flight on 27 th was instead commenced at an altitude of $700 \mathrm{~m}$. This was done to avoid low cloud near the southern end of
Table 1

SLFMR sea surface salinity surveys

\begin{tabular}{lllllll}
\hline $\begin{array}{l}\text { Day } \\
(2000)\end{array}$ & Start & Finish & Flight & Ferry & Survey & Altitude \\
& $(\mathrm{EST})$ & $(\mathrm{EST})$ & time (h) & time (h) & time (h) & $(\mathrm{km})$ \\
& $(\mathrm{hh}: \mathrm{mm})$ & $(\mathrm{hh}: \mathrm{mm})$ & & & & \\
\hline
\end{tabular}

(a) Cape Cleveland-Halifax Bay-Brook Island

(total area of four flight mosaic $=21,000 \mathrm{~km}^{2}$ )

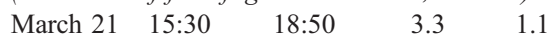

$\begin{array}{llll}16: 12 & 18: 23 & 2.2 & 3\end{array}$

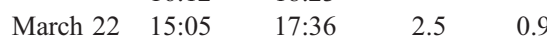

$\begin{array}{llll}15: 46 & 17: 19 & 1.6 & 3\end{array}$

March $22 \quad$ 18:41 22:13 19:35 23:05

March $23 \quad$ 15:22 20:00 $15: 55 \quad 19: 49$

Total

Mean

$4.5 \quad 1$

$\begin{array}{ll}4.6 & 0.7\end{array}$

$\begin{array}{ll}14.9 & 3.7\end{array}$

$3.5 \quad 3$

$3.9 \quad 3$

11.2

$2.8 \quad 3$

(b) Hinchinbrook Island (survey area $=2950 \mathrm{~km}^{2}$ )

\begin{tabular}{lrrrrrr} 
March 24 & $15: 42$ & $20: 02$ & 4.7 & 1.1 & & \\
& $16: 05$ & $19: 40$ & & & 3.6 & $1.0 / 1.5$ \\
March 27 & $14: 55$ & $19: 36$ & 4.7 & 0.9 & & \\
& $15: 27$ & $19: 14$ & & & 3.8 & $0.7 / 1.5$ \\
March 30 & $17: 23$ & $21: 33$ & 4.2 & 0.8 & & \\
& $17: 36$ & $21: 09$ & & & 3.6 & $1.0 / 1.5$ \\
Total & & & 13.6 & 2.8 & 11 & $0.9 / 1.5$ \\
Mean & & & 4.5 & 0.9 & 3.7 & $0.9 / 1.5$ \\
\hline
\end{tabular}

Hinchinbrook Island, which cleared as the survey progressed.

Most of the mapping flights were of about 4.5-h duration, of which about $3.5 \mathrm{~h}$ were spent on the actual survey (Table 1). Typical swath widths were $4 \mathrm{~km}$. At a flying height of about $1.5 \mathrm{~km}$, this enabled an area of approximately 3000 $\mathrm{km}^{2}$ to be covered at a representative cruising speed of 155 $\mathrm{kn}$ or $80 \mathrm{~m} \mathrm{~s}^{-1}$.

\subsubsection{Processing}

The data interface and manufacturer-supplied data acquisition software are described in Goodberlet (2000b, 2000c). This was adapted and modified in various ways to further enhance reliability and provide a real-time mapping capability. The modified software was verified against the original code and test data sets, and was validated using inflight data.

The SLFMR L-band brightness temperatures were computed using the manufacturer's instrument calibrations, and then converted to salinity using the Klein and Swift (1977) algorithm. The processing accounted for the variations in incidence angle of each beam and also compensated for aircraft roll using the aircraft navigation data. Brightness temperature corrections for downwelling and reflected upwelling atmospheric $\left(\mathrm{O}_{2}\right)$ emission, and for absorption due to atmospheric water vapor, both of which depend upon aircraft altitude, were also applied, but no correction was made for emissivity changes due to sea state variations.

A subset of the resulting salinities was then compared with the Pith Reef across-shelf CTD transect, and salinity offsets were computed for each beam. The resulting offsets 


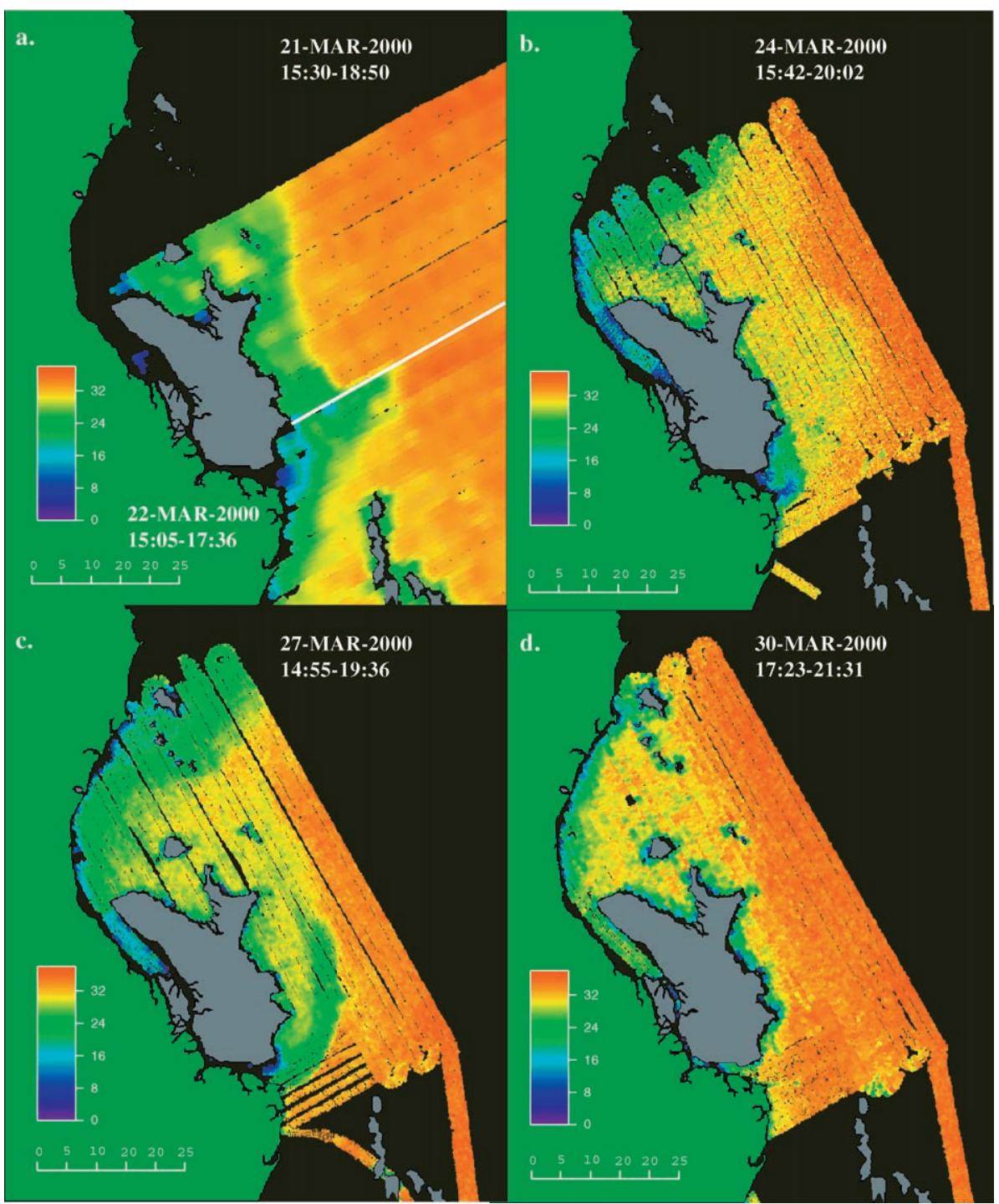

Fig. 3. Sea surface salinity SLFMR maps from flights at 3-day intervals (a)-(d), beginning on March 21. In (a), a partial map from the flight on March 22 is juxtaposed. Strong surface salinity gradients are prominent in all the maps with freshwater $(<16 \mathrm{psu})$ in the channel and along the coasts. A transition zone of intermediate salinity $(30-34 \mathrm{psu})$ marks the plume boundary.

were subtracted from all the data available from the corresponding beams. This step minimized the striping effect that resulted when only the manufacturer's brightness temperature calibrations were used. These offsets, which can differ by several Kelvin from beam to beam, can result from the gradual aging of components, but short-term variations due to such factors as warm up drift and humidity variations in the radome could also be responsible (see Section 2.3.1 for more details).

Noise levels were also reduced by smoothing the data from each beam in the along-track direction, using a moving average box car filter having a window length of $0.5 \mathrm{~km}$ for the high resolution (Hinchinbrook Island) maps, and of 4 $\mathrm{km}$ for the Halifax Bay data. The resulting smoothed maps appear in Fig. 3. In these maps, the elliptical footprints of each beam are plotted, but the corresponding salinity values are smoothed along track. The effect of the coarser footprint and larger filtering scale is evident in Fig. 3a, in which two of the Halifax Bay flights are shown juxtaposed. Because data from adjoining beams are not included in the filter window, the filter output of any particular beam is independent of the data in any other beam. This has the advantage of preserving across-track resolution, but produces a slight step-like variation within each scan, where across-track salinity gradients appear. The effect is most evident in the coarser resolution data (Fig. 3a).

\subsection{Oceanography and meteorology}

Oceanographic and meteorological data were acquired using a variety of in situ, fixed or moored, towed, and shipboard profiling instrumentation (see Stieglitz \& Steinberg, 2001 and BHSP2 for details). For the purpose of this paper, the water temperature, salinity, and depth measure- 
ments made at the locations shown in Fig. 1 (inset) are the most useful for assessing airborne salinity mapper performance. The data were obtained from six Sea Bird Electronics Seacat SBE 16-03 Conductivity and Temperature (CT) recorders and a Sea Bird SBE 19 Seacat Profiler Conductivity, Temperature, and Depth (CTD) recorder. Sample intervals were $10 \mathrm{~min}$ for the CT and $0.5 \mathrm{~s}$ for the CTD units. The CTD cast data were screened, bin-averaged typically into $1-\mathrm{m}$ bins, and smoothed with a 3- or 5-mlong box car filter, depending upon cast depth. During the screening step, data falling outside two standard deviations within each bin were eliminated. Only data acquired while the CTD was descending were accepted to ensure proper probe orientation and avoid self-induced mixing or contamination. Positions were determined using Traxar and Garmin GPS systems, with a precision better than $50 \mathrm{~m}$. All positions were referenced to World Geodetic System 84 (WGS 84).

The deployment and sampling schemes of the other oceanographic and meteorological instruments used for observing in situ tidal and wind-driven currents, marine winds, and surface gravity waves and their interpretation are described in detail in BHSP. Only a brief summary is given here. Tidal and wind-driven currents were measured using a variety of electromagnetic vector-averaging current meters and Acoustic Doppler Current Profilers (ADCPs) at locations designed to characterize the plume and ambient waters and along-shelf flow due to the East Australian Current. Marine wind data were acquired from the Australian Bureau of Meteorology weather station at the end of the 5-km-long Lucinda jetty. Finally, wave data were recorded by the S4 current meter operating in wave mode at Eva Island.

\subsection{Instrument calibration and errors}

\subsubsection{SLFMR accuracy and precision}

The SLFMR microwave brightness temperature output was calibrated at the laboratory by the manufacturer. When our field observations were converted to salinity values, a significant offset was found between the radiometer observations and a corresponding subset of the surface salinity samples, obtained from the Pith Reef cross-shelf transect CTD \#26-36 occupied on March 20 (Figs. 1 and 4). The resulting offset corrections, which were applied in the maps shown here (Fig. 3), were validated using an independent set of CTD data from the transects performed on March 22 and 27 (Fig. 5). The validation for both days using 10 available data pairs (Fig. 6) reveals considerable scatter $\left(R^{2}=0.5\right)$. The regression slope of 1.0, and bias of $1.2 \mathrm{psu}$, confirm that the instrument is capable of producing reasonable salinity estimates, although here they appear relatively noisy. The validation for individual days (Cases 1 and 3 for March 22 and 27 , respectively) was much less scattered $\left(R^{2}=0.9\right.$, 0.92 ) confirming the instrument design's linear response, at least over the short term. However, the regression slopes for these cases were smaller $(0.88,0.84)$, and the intercepts were larger $(6.9,4.7 \mathrm{psu}$, respectively). This suggests that the SLFMR response ranges more widely for given changes in CTD salinity, in contrast to the combined Case 2. It also indicates that significant offsets of order \pm 1.5 psu occurred on a day to day basis.

As this was the first field experiment employing the newly built Australian-owned SLFMR (serial \#2), which essentially duplicates the NOAA-owned prototype (serial \#1), some 'teething problems' were experienced. There were some indications of changes in absolute brightness

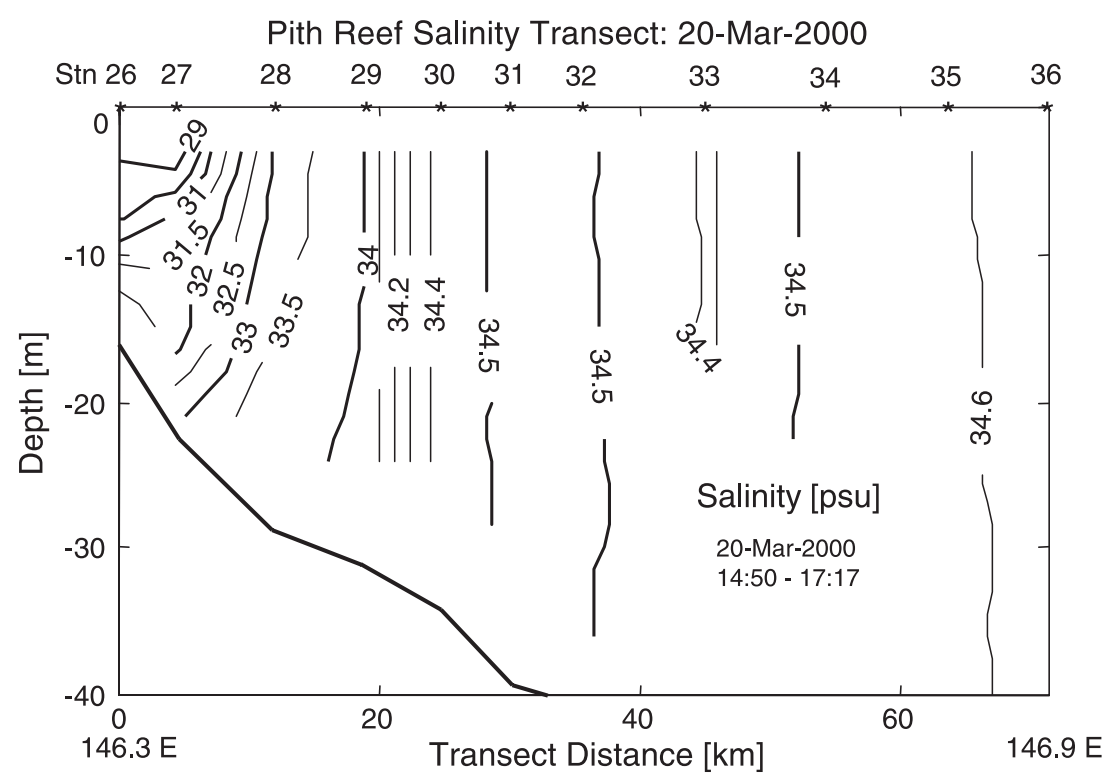

Fig. 4. Cross-shelf vertical salinity section between Brook Islands and Pith Reef (see Fig. 1 for transect location). CTD stations are marked with asterisks. Strongly sloping salinity gradients mark plume and outcropping front (Stns 26-29), while vertically homogeneous water and weaker horizontal gradients appear seaward of Stn 29. A slight near-surface freshening is evident at Stn 33. 


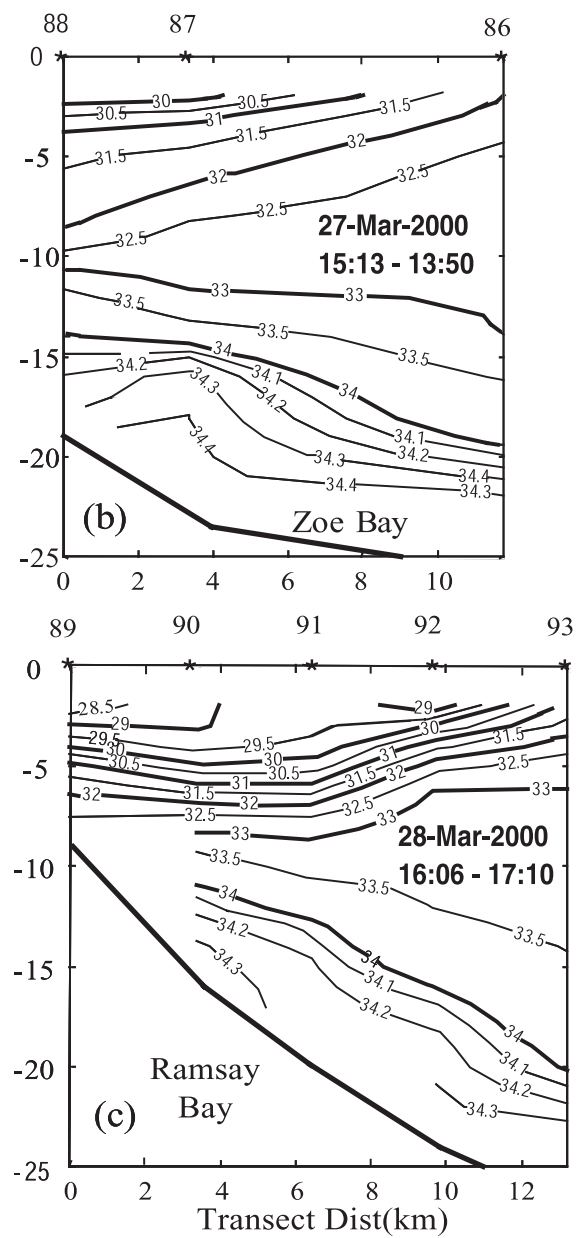

Fig. 5. Salinity sections starting (a) near the eastern channel entrance and proceeding in clockwise figure order up the east coast of Hinchinbrook Island past (b) Zoe and (c) Ramsay Bay into (d) Rockingham Bay. The plume intersects bottom near the entrance, but floats within the upper 10 m, subsequently as it flattens to the north then broadens into Rockingham Bay. A retrograde front is apparent offshore at depths exceeding $10 \mathrm{~m}$. Surfacing of the 29 -psu isohaline off Ramsay Bay (at Stn 91) coincides with saltier water penetrating the plume from the north in the sea surface salinity map acquired on the same day.

temperature early in each flight, and significant striping appeared in several of the maps, suggesting calibration biases in adjoining beams. Changes in specifications due to aging of components, which are possible over longer time scales (M.A. Goodberlet, personal communication, 1999), could explain the appearance of significant offsets. Another possibility is that galactic emission could have contaminated the 'cold sky' calibration measurements made at the manufacturer's laboratory to define the low end of the calibration range. While such effects could account for 'striping' artefacts, they are unlikely to account for variations over time scales of a few days. Estimation errors arising in the regression analysis of laboratory calibration data, due to collinearity in the various internal temperature values and the relatively restricted range of ambient and target temperatures, are possible sources of uncertainty. These could explain day to day variations in the influence of ambient and internal temperatures which may vary significantly from flight to flight. Recent experience suggests that insufficient instrument 'warm up', resulting in internal thermal disequilibrium early in the flights, could also be a factor. Addi- tionally, the appearance of free water in the radome due to high humidity in the moist tropical atmosphere (confirmed on a recent flight) could change the calibration. Closer monitoring and control of these factors is expected to improve validation in future flights. For the maps shown here, we advise caution in inferring changes in absolute salinity smaller than about 3 psu from day to day. At this stage, we have confidence in the significance of day to day changes greater than $3 \mathrm{psu}$, and in relative spatial changes within each map of order 1 psu.

Calibration experiments performed since the field work reported here indicate that accounting for Butler matrix temperature variations can mitigate or even remove the image striping artefacts (Prytz, Heron, Burrage, \& Goodberlet, 2002) and significantly reduce the drift. However, recalibration of the instrument before and after each mission is still desirable to minimize the effects of instrument drift.

\subsubsection{CTD calibration and sampling errors}

Water bottle samples were also acquired immediately below the surface as a check on in situ instrument perform- 


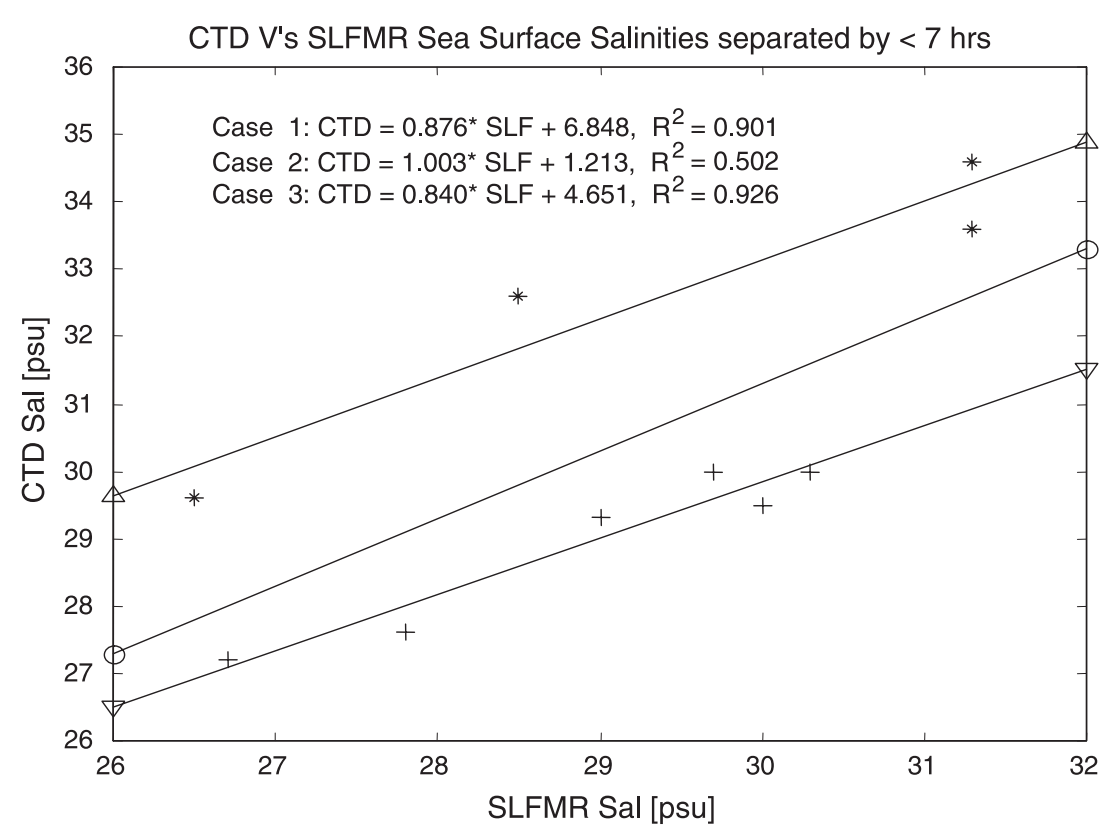

Fig. 6. Regression plot of CTD versus calibrated SLFMR sea surface salinities. The instrument was first calibrated using data from the Brook Island to Pith Reef CTD transect (Fig. 4). The validation shown here was based on independent data pairs selected from the remaining transects (Fig. 5). The triangles mark regressions for two different days (Cases 1 (top) and 3 (lower). The circles mark the regression for the pooled data set comprising 10 pairs (Case 2). The instrument appears stable and linear on a daily basis, but interday calibration changes are evident. All data pairs were collected $7 \mathrm{~h}$ apart or less; some intraday scatter could result from tidal advection.

ance and for verifying the manufacturer's calibration. These were matched with CTD values from a corresponding level. The samples were analyzed using a laboratory standard inductive salinometer. A regression of CTD versus 21 bottle salinities in the range 2-35 psu produced a slope and offset not significantly different from unity and zero, respectively $\left(R^{2}=0.995\right)$, and a standard deviation (sampling error) of 0.5 psu (Stieglitz \& Steinberg, 2001). Hence, no modifications were made to the manufacturer calibrations. Instrumental errors, as indicated by manufacturer specifications, were negligible in comparison with the sampling errors. These sampling errors may have arisen from the effects of near-surface salinity gradients acting in concert with horizontal positioning errors and short sampling delays, incurred while 'on station'.

\section{The mapping experiment}

The airborne mapping operations (Table 1) comprised three main activities: (1) a mosaic of four flights conducted over a 3-day period to survey the extensive Burdekin River plume within Halifax Bay and to the edge of the continental shelf between Cape Cleveland and Brook Island (also spanning Hinchinbrook Island); (2) three intensive overflights in the vicinity of Hinchinbrook Island, to map the surface salinity distribution associated with the Herbert and Tully River plumes at 3-day intervals; (3) additional flights off Cape Cleveland optimized for studying the effects of surface roughness, and reflected solar and galactic emis- sions. Only the two northernmost flights from the Halifax Bay mosaic (Fig. 3a) and the Hinchinbrook Island surveys (Fig. 3b-d) are reported here. The other flight results will be reported elsewhere.

In preparation for the experiment, the AIMS RV Lady Basten (27 m) was used from March 10 to 21, 2000 to lay oceanographic moorings and perform reconnaissance across-shelf transects of CTD casts in the study area (Fig. 1). Overflights by the Cessna 404 with the SLFMR commenced near Hinchinbrook Island on the afternoon of March 21 and continued at approximately 3-day intervals over a 10-day period. The flights generally spanned a rectangular area that included the north and southeast arm of the Hinchinbrook Channel, which runs along the western and southern side of the Island, and ranged south to Orpheus Island, north to Dunk Island (Fig. 1, inset), and east to the middle of the continental shelf (Fig. 3). The Herbert River flows into the channel near its southeast end, at which point the river flow is divided between the north and southeast arms; the Tully River flows into Rockingham Bay, just south of Dunk Island. The first two Halifax Bay flights were made on March 21 and 22. Being flown at higher altitude, the resulting maps were of relatively low spatial resolution (Fig. 3a). In contrast, the Hinchinbrook overflights (Fig. $3 b-d)$, which began with the initial shelf-scale survey on March 24 and were repeated on March 27 and 30 (see Table 1 for details), were of higher resolution.

Within this intensive survey period (March 20-31), in situ water sampling, CT Tows, CTD casts, and underway ADCP profiles were performed from a fast 8-m launch, RV 
Titan, operating out of Orpheus Island (BHSP describes the ADCP results). Beginning on March 23, a CT instrument was deployed at the seaward end of the $5.8-\mathrm{km}-$ long Lucinda Jetty, located near the southeast mouth of Hinchinbrook Channel. At the end of the flight survey period, two additional CT units were installed midway along the jetty, and on a trawler mooring in the channel about $4 \mathrm{~km}$ in from the channel mouth. Their purpose was to acquire salinity time series near the source and both inside and just outside the plume, depending upon tidal stage, and to monitor the plume's evolution during the extended period (March $31-$ May 8) of the experiment. Their deployment period spanned the landfall of two TCs, 'Tessi' and 'Vaughan', on April 3 and 6 , respectively. The moored instrumentation was recovered during May 5-7.

\section{Structure of the Herbert River plume}

\subsection{Horizontal structure}

The sea surface salinity maps obtained from the SLFMR overflights show variations in the extent of the Herbert and Tully River plumes over a period of 10 days (Fig. 3). On March 21, the Herbert River plume emanating from the southeast end of Hinchinbrook Channel exhibits moderate to strong development, with a band of low salinity water $(<30$ psu, upper part of Fig. 3a) spread along the eastern shore of Hinchinbrook Island and into Rockingham Bay. By the 22nd, the plume has enlarged and spread seaward off the southeast corner of the island (lower part of Fig. 3a). There is evidence of some seawater dilution seaward of this plume, in the mid-shelf areas, particularly around the Palm Island group in the SE corner of the domain. Quite freshwater $(<16 \mathrm{psu}$, denoted 'fresh', henceforth, though not fresh in an absolute sense) lies around the northern and eastern end of Hinchinbrook Channel, and there is evidence of a thin band of such water following the eastern shoreline of the island. Since the closest one or two pixels could be affected by sidelobe contamination due to terrestrial emission, we cannot draw a firm conclusion on freshwater occurrence where the width of the band is of this order, but there are zones where it is significantly wider.

On March 24, the extent of 'moderately fresh' water (16 to $30 \mathrm{psu}$ ) is reduced to a narrow band along the island coastline, but the Herbert River plume emanating from the eastern branch is still substantial and fresh near the mouth (Fig. 3b). There is an extended surface water mass of 'intermediate' salinity (30-34 psu), lying in a broad band that appears seaward of the channel entrance and spreads northeast and then north northwest inside the two seawardmost flight legs. The extent of moderately freshwater inside Rockingham Bay appears little changed.

Three days later, on the 27th, this moderately freshwater is confined closer to the coast (Fig. 3c). There is a newly surveyed region off the Tully River mouth in the north of the bay, which suggests the presence of a separate freshwater plume. Intermediate water is still present in a broad band west of the outer two flight lines, but a new feature has emerged. An arcuate plume of moderately freshwater extends east from the southeast channel entrance and curves anticyclonically (i.e., anticlockwise) to a point seaward of the northeast corner of the island. Narrow and partly isolated bands of freshwater persist along the east coast of the island. Consequently, there is a tongue of intermediate water reaching southward between the plume and the island's eastern side that produces a local salinity maximum. Possible dynamical origins of this feature are discussed in the companion paper (BHPSP2).

By March 30, there is no indication of freshwater input from the southeastern mouth of Hinchinbrook Channel, and the arcuate plume has disappeared. Only remnant patches of moderately freshwater lie off the island's eastern shore, with a narrow band of freshwater clinging to the central eastern and northern coast of the island (Fig. 3d). This coastal fresh band, which appears in all of the flight maps obtained from March 24 and onward, could represent a line source of freshwater emanating from the beaches and wetlands lying along the island's shore that is largely independent of river discharge events. A large body of intermediate salinity water still lies north of the island in Rockingham Bay, but the extent of the Tully River plume at the northern end of the bay is much reduced. The salinity in the northwest arm of Hinchinbrook Channel has also significantly increased, consistent with reduction of size of the Herbert River plume.

\subsection{Vertical structure}

The vertical structure of the Herbert and Tully River plumes were investigated using a combination of the shipboard CTD temperature and salinity profiles and in situ current meter mooring measurements. CTD profiles were obtained along several transects spanning the continental shelf, extending eastward from the coastal town of Lucinda and Hinchinbrook Island, following the Hinchinbrook Channel west of the Island, and crossing Rockingham Bay (Fig. 1).

\subsubsection{Hinchinbrook Island to shelf edge}

Selected vertical sections along these transects are shown in Figs. 4, 5, and 7. The start and finish times and positions of these transects are shown in Table 2 along with the cast station numbers, which increase in the same order in which they were occupied.

The across-shelf transect (Fig. 4) shows that on March 20,1 day prior to our first flight, waters seaward of a point $20 \mathrm{~km}$ east of Brook Islands were vertically well mixed to distances offshore of about $72 \mathrm{~km}$ and depths of at least 40 $\mathrm{m}$. This point approximately coincides with the transition from relatively open lagoon waters to the barrier reef matrix lying on the outer shelf. Within this region, the salinity increased rapidly from 34.1 to 34.5 psu over a distance of 
about $10 \mathrm{~km}$, then more gradually to 34.6 psu to the seaward end of the transect. A weak salinity minimum of 34.4 psu was indicated at CTD Stn 33.

Shoreward of the $20-\mathrm{km}$ point, vertical salinity gradients appear and strengthen as the Brook Islands are approached, with the isohalines developing a distinct plume-like character between CTD Stns 28 and 26. In the corresponding salinity maps (Fig. 3a), the transition from 32 to 34 psu water appears at approximately the location of CTD Stn 28 , where surface salinities are about $33 \mathrm{psu}$. The isohalines become more nearly vertical and the horizontal salinity gradient gradually weakens seaward of Stn 29, where the gradient is similarly diffuse in the flight data. The relatively diffuse horizontal salinity gradient may be due to the stronger wind stress (Fig. 2b) which occurred early in the morning of March 21 and prior to the afternoon flight.

The Lucinda transect (Fig. 5a), conducted on March 22, shows a strongly stratified plume structure near the eastern channel mouth with salinity varying from 29.0 to $33.0 \mathrm{psu}$ (at Stn 54), then a steeply inclined frontal interface (slope 15 $\mathrm{m} / 7 \mathrm{~km}$, or $2.14 \times 10^{-3}$ ) outcropping in the range 33.0 to 33.7 psu between Stns 54 and 55, about $18 \mathrm{~km}$ offshore. Beyond this, the near-surface waters appear well mixed
Table 2

CTD transect summary

\begin{tabular}{llllll}
\hline $\begin{array}{l}\text { Transect } \\
\text { name }\end{array}$ & $\begin{array}{l}\text { Cast\# } \\
\text { first-last }\end{array}$ & $\begin{array}{l}\text { March } \\
\text { date }\end{array}$ & $\begin{array}{l}\text { Start-finish } \\
\text { time } \\
\text { (hh:mm) }\end{array}$ & $\begin{array}{l}\text { Start/finish } \\
\text { lat(S) } \\
\text { (dd mm m) }\end{array}$ & $\begin{array}{l}\text { Start/finish } \\
\text { lon(E) } \\
(\mathrm{dd} \mathrm{mm} \mathrm{m})\end{array}$ \\
\hline Pith Reef & $26-36$ & 20 & $13: 12-21: 32$ & $1809.86^{\prime}$ & $14616.53^{\prime}$ \\
& & & & $1811.19^{\prime}$ & $14656.99^{\prime}$ \\
Lucinda & $51-56$ & 22 & $13: 46-17: 16$ & $1830.41^{\prime}$ & $14623.19^{\prime}$ \\
& & & & $1829.92^{\prime}$ & $14635.45^{\prime}$ \\
Zoe Bay & $88-86$ & 27 & $13: 50-15: 09$ & $1823.29^{\prime}$ & $14621.66^{\prime}$ \\
& & & & $1822.95^{\prime}$ & $14628.35^{\prime}$ \\
Ramsay Bay & $89-93$ & 27 & $16: 07-16: 57$ & $1819.54^{\prime}$ & $14617.78^{\prime}$ \\
& & & & $1817.34^{\prime}$ & $14624.93^{\prime}$ \\
Brook Island & $94-101$ & 28 & $13: 24-14: 47$ & $1807.53^{\prime}$ & $14617.20^{\prime}$ \\
& & & & $1807.41^{\prime}$ & $14602.52^{\prime}$ \\
Hinch. Ch.\#1 & $76-68$ & 26 & $12: 34-16: 08$ & $1829.62^{\prime}$ & $14617.19^{\prime}$ \\
& & & & $1812.49^{\prime}$ & $14603.66^{\prime}$ \\
Rock'ham & $108-102$ & 28 & $16: 36-18: 42$ & $1816.69^{\prime}$ & $14603.96^{\prime}$ \\
$\quad \begin{array}{l}\text { Bay\#1 } \\
\text { Hinch. Ch\#2 }\end{array}$ & $122-113$ & 29 & $13: 50-16: 34$ & $1829.62^{\prime}$ & $14617.19^{\prime}$ \\
& & & & $1812.48^{\prime}$ & $14603.64^{\prime}$ \\
Rock'ham & $115-109$ & 29 & $12: 58-14: 12$ & $1816.91^{\prime}$ & $14603.87^{\prime}$ \\
Bay\#2 & & & & $1802.16^{\prime}$ & $14606.28^{\prime}$ \\
\hline
\end{tabular}

down to depths of $10 \mathrm{~m}$, below which the stratification resembles a bottom trapped retrograde front (Bowman \& Esaias, 1978). Surface salinity gradients range from about
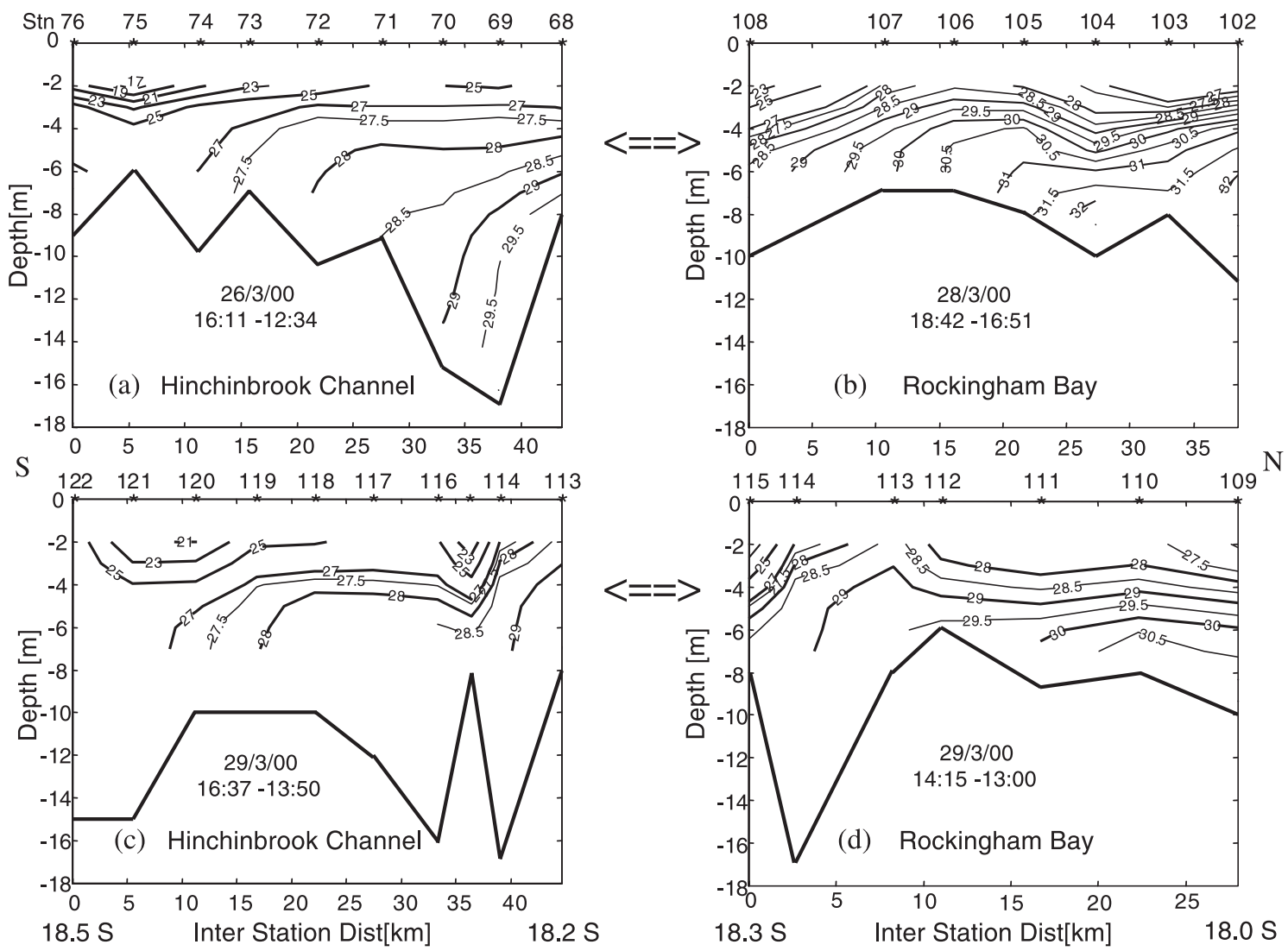

Fig. 7. Salinity sections along Hinchinbrook Channel (a and c) between the Herbert River mouth (at Stns 77 and 121, which are coincident) and the northern channel entrance and across the western margin of Rockingham Bay from the entrance to Dunk Island ( $b$ and d; see Fig. 1 for locations). The prominent salt wedge in the channel sections is disrupted by anomalously fresh (c), while the bay sections show the diminishing influence of the Tully River plume (near Stns 101 and 110). 
$0.50 \mathrm{psu} \mathrm{km}^{-1}$ near the mouth (Stn 51) to $0.15 \mathrm{psu} \mathrm{km}^{-1}$ near Stn 55. In this transect, the appearance of the frontal structure and 33-psu isohaline at Stn 54 may be compared with the 32-34 psu boundary evident in the sea surface salinity map obtained on the same day (Fig. 3a).

The Zoe Bay transect (Fig. 5b), conducted 5 days later on March 27, shows a broader plume structure with salinity varying from less than 30 to 32 psu over a distance of about $12 \mathrm{~km}\left(0.17 \mathrm{psu} \mathrm{km}{ }^{-1}\right)$ near the surface. There is a relatively homogeneous wedge of slightly higher salinity water (32-33 psu) centred at about 10-m depth. Beneath this level to depths of about $20 \mathrm{~m}$, the interface slope is reversed. This suggests a near bottom prograde front, in contrast to the retrograde front off Lucinda. However, with only three CTD stations along this transect, spatial details are not resolved. The better-resolved Ramsay Bay transect (Fig. 5c), also obtained on March 27, shows a slightly broader structure which otherwise strongly resembles that off Zoe Bay (Fig. 5b). A distinctly different feature is localized shallowing of the 29-psu isohaline at Stn 91. This feature is associated with a shallow tongue of relatively saline water penetrating the body of the plume (see below). It is embedded in an average salinity gradient that increases seaward at about $0.19 \mathrm{psu} \mathrm{km}^{-1}$ over the length of the transect. Near-surface salinity changes from 29 to $31 \mathrm{psu}$ between the last two stations $\left(0.67 \mathrm{psu} \mathrm{km}^{-1}\right)$, about $12 \mathrm{~km}$ off shore.

The Zoe and Ramsay Bay transects exhibit a plume-like retrograde frontal structure in the upper $10 \mathrm{~m}$, consistent with the presence of a coastal river plume. Beneath this level, the isohaline slope reverses to form a prograde frontal feature within which salinity actually decreases seaward. The origin of this feature is not immediately apparent. It may be due to a larger-scale plume offshore that is derived from more southerly sources such as the Burdekin River, or it may be related to the larger-scale shelf-scale circulation. In the near surface, these transects may be compared with the sea surface salinity map from our fourth flight (Fig. 3c). The distinct higher-salinity tongue, mentioned previously, coincides with the local salinity maximum evident near the surface in the Ramsay Bay CTD transect (Fig. 7c). The sea surface salinity map shows this tongue penetrating past Zoe Bay almost to Lucinda. In this case, the maximum is not evident in the Zoe Bay CTD transect. Due to depth filtering, the CTD contours extend only to within $2.5 \mathrm{~m}$ of the surface, so spatial resolution is poor. It is thus quite possible that the feature was shallower and missed by the sampling at this location.

The Brook Island transect (Fig. 5d) obtained a day later, on March 28, shows strong vertical stratification outlining a very broad near-surface plume. The minimum salinity of about 27.5 psu appears between Stns 99 and 100 (CTD Stn numbers increase westwards along the Brook Island and Zoe Bay transects). At depths of between 5 and $15 \mathrm{~m}$, there is a very gently sloping retrograde frontal structure which steepens and outcrops at the 2-m depth level between the last two stations (94 and 95) with a salinity of about 31 psu. Near-surface salinity gradients average about $0.16 \mathrm{psu}$ $\mathrm{km}^{-1}$ between the local minimum and Stn 95, and are about $0.40 \mathrm{psu} \mathrm{km}^{-1}$ seaward of that point. A corresponding front (salinity 31 to $33 \mathrm{psu}$ ) appeared about $6 \mathrm{~km}$ seaward of Brook Island on the March 27 sea surface salinity map and moved shoreward, almost to the island, by March 30 (Fig. 2c and d).

\subsubsection{Hinchinbrook Channel and Rockingham Bay}

Transects through the Hinchinbrook Channel and northward parallelling the west coast of Rockingham Bay (Fig. 7) exhibit a salinity structure which resembles that of a salt wedge estuary. The first channel transect conducted on March 26 (Fig. 7a) begins at the river mouth (Stn 76) and reaches about $5 \mathrm{~km}$ north of the northwest channel entrance (Stn 68). Salinities are less than 17 psu just north of the river mouth and increase to $25 \mathrm{psu}$ at the channel entrance. The salt wedge extends from Stn 74, where the 27-psu isohaline contacts the bottom, to (and possibly beyond) the end of the transect in Rockingham Bay, where bottom salinities exceed $29.5 \mathrm{psu}$. We would expect the form and the location of the wedge to depend significantly on the phase of the tide. However, an identical transect completed the same day, $2 \mathrm{~h}$ prior to that shown $(10: 05-12: 34)$ but traversed in the reverse direction, differed only in minor ways from the one shown.

The Rockingham Bay transect (Fig. 7b), conducted 2 days later, extends the channel transect northward, and overlaps with it at the southern end, beginning at the second last station (Stn 69, Fig. 7a). In the bay transect, the salt wedge interface appears more intense and is located further north. These transect differences appear too large to be explained by the 2 -h difference in tidal phase between these traverses. The salt wedge influence extends to about the centre of the Rockingham Bay transect at which point isohaline gradients reverse, presumably due to the influence of the Tully River plume. Salinities apparently reach the local minimum of 27 psu right near the Tully mouth, which lies close to the second last station (Stn 103).

The times of these two transects (Fig. 7a and b) span the fourth SLFMR flight on March 27 (Fig. 3c). During this flight, surface salinities in the range 12 to 25 psu were mapped within the northern half of the channel (data from the southern half suffers main and side-lobe contamination from land at either side of the channel, and is anomalously low). The transition to higher salinity values $(>25 \mathrm{psu})$ is fairly sharp and confined to the channel entrance and a thin fresh band following the west coast of the bay. In the bay CTD transect (Fig. 7b), this transition occurs between CTD Stns 108 and 107, which span the northeast channel entrance, indicating close agreement with the SLFMR map.

The channel transect obtained 3 days later, on March 29 (Fig. 7c), shows the same structure, but the plume is more saline (minimum of $21 \mathrm{psu}$ ) and the salt wedge is distorted by the presence of a relatively fresh, $2 \mathrm{~m}$ thick, well-mixed 
layer of low salinity water near the northwest end of the channel (local minimum 23 psu). This occurs near CTD Stn 115 , and its location coincides with that of the low salinity patches present inside the northeast channel during the flights of March 24 and 27. We are confident this feature is not an instrumental artefact, but its source is unknown. There are extensive mangrove wetlands and tidal inlets, but no freshwater creeks or rivers close by, so it is presumably derived from the Herbert or the Seymour River, both located near the southern end of the channel. The feature was not evident during the flight of March 30. This flight occurred after a significant pulse of stronger winds (Fig. 2b), so the feature was probably destroyed by wind-induced vertical mixing prior to the flight.

The corresponding Rockingham Bay transect obtained the same day (Fig. 7d) is overlapped using data from the last three stations of the channel transect (Fig. 7c). As the third and fourth stations (Stns 113 and 112, respectively) were occupied just 10 min apart, the change in sign of isohaline slope at Stn 113 is real. This change occurs further south than its location on the previous day (Stn 106, Fig. 7b), and the underlying stratification to the north is weaker (the 27psu isohaline has contracted to the north, but lower layer salinities have also reduced significantly). The Tully River plume has apparently dispersed significantly during the intervening period. This could be due to a combination of factors such as reduced river flow, strengthening northward current flow, enhanced tidal mixing, and increased wind stress and associated wave action (Fig. 2 and BHSP2). In any case, the SLFMR map obtained on March 30 shows a much reduced Tully plume in the north of Rockingham Bay, with significantly more saline water $(>34)$ encroaching on the inner shelf. Waters along the axis of Hinchinbrook Channel are also significantly more saline.

\subsection{Zone of influence}

The combination of in situ and airborne salinity observations that we have used to determine horizontal and vertical structure provides an opportunity to assess the zone of influence of the Herbert and Tully River plumes. Under the conditions prevailing during the experiment, it is clear that this influence was confined to Hinchinbrook Channel and the inner continental shelf. The maximum across-shelf spread of the plume from Hinchinbrook Island, seaward, as observed in the flight of March 24, corresponded approximately to the width of the island. It thus occupied a significant fraction (over 50\%) of the width of the GBR lagoon, at the latitude of the island, but did not reach the barrier reef matrix on the outer shelf.

With the exception of the area mapped on March 22, which might have been affected by the more extensive Burdekin River plume originating to the south, the maximum southward (poleward) extent of the Herbert River plume was approximately $5 \mathrm{~km}$ south of the channel entrance at Lucinda. The northern (equatorward) extent of the plume is more difficult to determine from the airborne surface salinity maps since it evidently merged with that of the Tully River. Freshwater entering the channel from the Herbert River mouth, which is located near the southeast end of Hinchinbrook Channel, divides into two parts. One flows through the remaining stretch of the southeast arm where it enters the sea at Lucinda, and the other flows northwest and reaches along the northwest arm from which it enters Rockingham Bay. The bay apparently receives freshwater from both sources, but the relative freshwater discharge of these two sources of Herbert River water is not known. The flight data suggest, and the in situ CTD transects confirm, that the outflow from the northwest arm has more influence on surface salinities inside the bay, particularly near the coast. The CTD transects suggest that the southern half of the bay is most strongly influenced by Herbert River water emanating from the northwest arm of the channel, while the northern half of the bay is significantly influenced, if not dominated, by the Tully River plume.

The water column was vertically stratified out to the 30 $m$ isobath during the CTD transect on March 20, and vertically well mixed in the deeper water, when the river discharge was relatively strong. The seaward extent of this stratified zone was not clearly defined by the remaining transects executed during March 22-28, but it evidently extended to at least the $20-\mathrm{m}$ isobath, in spite of the steadily reducing river discharge. However, the inclined frontal interface, as defined by the 33-psu isohaline, was observed intersecting the bed on the Lucinda and Brook Island transect, at depths of 15 and $10 \mathrm{~m}$, respectively. The prevailing conditions were dominated by weak southward then northward (i.e., reversing) along-shelf drift, while wind and tide-induced mixing were only significant right at the beginning and at the end of the flight survey period. The prevailing currents, combined with the effect of diminishing river discharge, and the influence of Coriolis deflection largely confined the plume to the inner half of the lagoon. The possibility that other prevailing hydrological, oceanographic, and meteorological conditions could significantly expand or otherwise modify the observed zone of influence is discussed in the companion paper (BHSP2).

\section{Performance assessment}

\subsection{Representativeness of surface salinity distribution}

Due to constraints on the effective depth of emission of L-band electromagnetic radiation, the SLFMR observations are restricted to a 5-cm-thick surface layer. It is thus appropriate to consider under what circumstances this layer is representative of the subsurface structure. In the case of our large-scale across-shelf transect (Fig. 4), surface salinities were obviously representative of the (vertically homo- 
genous) subsurface conditions observed in the GBR matrix and outer shelf, where vertical mixing is sufficiently strong to overcome any stratification tendencies. Clearly independent information (e.g., model results or sampling statistics) is required to determine under what circumstances the shelf water might be unstratified. In general, though, when there is likely to be strong vertical mixing and horizontally opposed fresh and saline water sources, the remote sensing method should provide surface information that may be safely extrapolated downwards. One example could be vertically homogeneous estuaries subject to strong vertical mixing due to tidal action or winds. Depending upon the width of such an estuary, it may be laterally homogeneous or inhomogeneous. Another example could be a large shallow tidal embayment with a combination of strong heating leading to evaporative concentration of seawater and sea breeze effects such as at Shark Bay or Exmouth Gulf on the arid NW coast of Western Australia. In a stratified situation, the method could be useful to identify when upwelling conditions pertain, but it may be difficult to distinguish this situation from that of horizontal advection of a saline or freshwater source. A case in point is the tongue of higher salinity water penetrating the plume in the map of March 27. Taken in isolation, the SLFMR data suggest southward advection (Fig. 3c), while the CTD transect suggests doming of the isohalines (Fig. 5c). In both cases, we are limited to a 2-D view, whether horizontal or vertical. A 3-D representation is really needed to fully describe the water column structure and circulation. This circulation feature evidently has a deeper dynamical significance (see BHSP2).

Clearly, passive microwave radiometry for determining sea surface salinity is no different from numerous other remote sensing techniques (infrared radiometry, radar altimetry, ocean colour, etc.) in their requirement for in situ data, at least for validation, if not for interpretation. However, like the other techniques, it also brings all the advantages of a near real-time synoptic view of the ocean surface, which cannot be obtained by any other means. As such, it obviously constitutes an important new tool for observing and interpreting coastal oceanographic features and processes.

\subsection{Performance of the SLFMR}

The performance of the SLFMR was clearly adequate for its intended purpose, i.e., to map the surface distribution of salinity in the presence of a coastal river plume. Instrument precision was of order $1 \mathrm{psu}$, which is adequate for mapping coastal plumes originating from rivers with moderate discharge levels. While, under the circumstances, day to day instrumental accuracy was less than desired ( $\sim 3 \mathrm{psu})$, the instrument evidently performed linearly, and with adequate stability and precision, on each flying day. The results are comparable in quality with those obtained by Miller et al. (1998) using the prototype SLFMR. They observed the
Chesapeake Bay plume produced by a high river discharge and obtained agreement between the SLFMR and in situ salinities within \pm 4 psu over a $12-27$ psu range. Le Vine et al. (1998) surveyed the Delaware Coastal Current using ESTAR and a coastal research vessel. The resulting sea surface salinity map agreed within \pm 2 psu with shipboard CTD data.

\subsection{Utility of airborne surface salinity mapping}

The airborne salinity mapping system proved to be an efficient and effective method of obtaining a synoptic view of the surface salinity distribution in a significant portion of the Great Barrier Reef Lagoon. Actual areas mapped were about $2950 \mathrm{~km}^{2}$ for the Hinchinbrook Island flights and $21,000 \mathrm{~km}^{2}$ for the entire Halifax Bay domain (mosaic of four flights). Thus, a total of $8850 \mathrm{~km}^{2}$ was surveyed in $11 \mathrm{~h}$ from an altitude of $1.5 \mathrm{~km}$ (max) with a typical resolution of about $0.5 \mathrm{~km}$ over Hinchinbrook Island. A total of 21,000 $\mathrm{km}^{2}$ was surveyed in just $11.2 \mathrm{~h}$ at $3.0-\mathrm{km}$ altitude over Halifax Bay (including the Hinchinbrook Island area) at a reduced resolution of $1.0 \mathrm{~km}$. This yields representative survey coverages of about $800 \mathrm{~km}^{2} / \mathrm{h}$ at $0.5-\mathrm{km}$ resolution and of $1900 \mathrm{~km}^{2} / \mathrm{h}$ at $1.0-\mathrm{km}$ resolution, respectively.

The utility of airborne passive microwave radiometry for mesoscale sea surface salinity mapping can be contrasted with the alternative of making salinity observations from a surface vessel. Wolanski and Jones (1981) and Wolanski and Van Senden (1983) used multiship surveys during the 1979-1980 and 1980-1981 summers to map the Burdekin River flood plume repeatedly over a several week period in a $380-\mathrm{km}$ stretch from its source near Cape Upstart (lat $19.7^{\circ} \mathrm{S}$ ) to a point north of Cairns (lat $16.8^{\circ} \mathrm{S}$ ). Multiple surveys were carried out at weekly intervals. Using the SLFMR, a comparable single survey comprising a mosaic of four flights, averaging 3.8-h duration, was achieved in 3 days and could potentially have been executed in 2 days. While the observed domains were also comparable in area, the resolution of the airborne data was naturally much greater, with samples spaced about $1 \mathrm{~km}$ apart throughout the domain. Clearly, the combined use of airborne mapping and complementary ground-truth operations is an efficient means for mapping surface salinity distributions in coastal settings.

Apart from the enhanced sampling speed, resolution, and flexibility inherent in the airborne method, there are a number of other advantages. This near-surface layer (top 5 $\mathrm{cm}$ ) is difficult to resolve consistently using a conventional CTD. It also allows mapping over extended shallow water areas; even close to land boundaries, if low flight altitudes are used to avoid side-lobe contamination. These are inaccessible to all but the smallest surface vessels. It is relatively unaffected operationally by sea state, although roughness variations have influences on the salinity retrieval, which could necessitate correction, and such influences are now being investigated. 
Some disadvantages are also apparent. The microwave observations are susceptible to sun and galactic glint, which limits the range of flying times that are considered optimal (in our case, to late afternoon). The measurement is inherently noisier and consequently poorer in precision and less certain in accuracy, in comparison with CTDs or water samples. However, it integrates over a finite surface area (about $3 \mathrm{~km}^{2}$ ), in contrast to pointwise CTD sampling. While the microwave system can penetrate cloud (but not heavy rain), the companion infrared system for observing sea surface temperature cannot. This is not serious in the tropics because the microwave observations are relatively insensitive to variations at elevated sea surface temperatures, but could be a problem in temperate or polar regions. Other techniques for observing sea surface temperature such as $\mathrm{C}$-band microwave radiometry could be considered to provide temperature measurements under cloudy conditions. As for the most marine remote sensing techniques, the brightness temperature measurements are restricted to a thin surface layer, so vertical structure is inaccessible under stratified (vertically inhomogeneous) conditions. In contrast, towed or profiling CTDs can efficiently determine vertical structure, at least in two spatial dimensions.

In addition to instrument performance, observing platform effectiveness is also relevant. Light aircraft (whether single or twin-engined) operate under regulatory restrictions that can limit flight opportunities significantly. Examples include the necessity to have instrument installations carefully engineered, tested, and approved by the relevant aviation authorities to ensure aircraft safety and restrictions on flight duration and frequency to avoid pilot fatigue, adverse weather, and blind-flying conditions. Ships operate under less severe regulatory constraints, at least as far as instrument installation is concerned, but are also constrained operationally by adverse weather conditions. While the operational and standby costs of such aircraft are comparable with those of coastal research vessels, they are offset by the faster sampling rate of the aircraft. Finally, navigational requirements for the SLFMR (for both positioning and pointing) are moderately demanding. A high-performance vector GPS system giving precise and accurate 3-D aircraft position (latitude, longitude, and altitude) and attitude (pitch, roll, and heading) data is a basic requirement, particularly for light aircraft that are subject to rapid accelerations. This contrasts with traditional CTD surveys conducted on slower moving ships that require quite simple and inexpensive 2-D GPS position fixing equipment and pressure gauges for horizontal and vertical positioning, respectively.

\subsection{Future enhancements}

Significant enhancements are expected from a number of operational improvements. More thorough and more frequent laboratory calibration, involving a wide range of target and instrument thermal conditions, should eliminate the interchannel striping evident in the survey maps, and allow accurate mosaics to be built up from adjoining flight domains, without a need for extensive in situ data. Longer warm-up time should avoid the instrument drift and hence salinity biases experienced early in the flights reported here. High humidity in the tropical atmosphere, leading to presence of free water in the radome, with likely adverse effects on antenna response, has been identified as a possible error source in more recent flights. This will be carefully monitored and avoided, or at least ameliorated, using such techniques as a nitrogen purge before or during future flights. Recent introduction of a multichannel push-broom infrared radiometer system promises to give independent thermal information on plume development, as well as improved temperature corrections in the salinity retrievals. The operations reported here were confined to use of a single-channel infrared radiometer system.

Improvements in sensitivity are also quite feasible. The present instrument makes provision for wide band width operation (100 MHz instead of the standard $25 \mathrm{MHz}$ span of the astronomical band), but we have not yet calibrated it for this mode of operation. This mode should be useful where Radio Frequency Interference (RFI) from such sources as coastal radars is negligible or avoidable, and should significantly improve the sensitivity and hence radiometric resolution of the instrument under such circumstances. Unfortunately, the wide band width mode was found to be inappropriate during tests of the US SLFMR in the vicinity of Washington, DC, where significant RFI levels were detected, due presumably to the high concentration of civilian and military radars operating in the Chesapeake Bay region (Goodberlet et al, 1997). As this technology becomes more widely used, we might find instances of RFI within the $25-\mathrm{MHz}$ protected band centred at $1.413 \mathrm{GHz}$, which could demand new sampling strategies. A new truly multichannel version of the instrument, STARRS, recently constructed for the US Navy, is being tested operationally. This theoretically improves sensitivity by a factor of 2.5 , by allowing all six antenna beams to be observed simultaneously and continuously by dedicated radiometer assemblies, rather than being polled sequentially and multiplexed through a single radiometer. Additional design features are expected to yield an overall factor of 6 improvement in sensitivity (M.A. Goodberlet, personal communication, 2001). Finally, a multifrequency C-band radiometer has been added to the STARRS instrument package. This allows nearly simultaneous observations of surface roughness effects, and will facilitate development of enhanced algorithms for correcting for the consequential emissivity variations.

Once the calibration issues are resolved and sensitivity is improved, we anticipate that the range of applications will expand to include more subtle expressions of sea surface salinity variability, such as are found under low river inflow conditions or over the outer continental shelf and continental slope. 


\section{Conclusions}

We have successfully deployed an airborne salinity mapper, SLFMR Serial No. 2, in a topographically complex environment to map representative tropical river plumes in the Great Barrier Reef Lagoon. The results, when combined with data from in situ instrumentation, give a comprehensive view of the horizontal and vertical structure of the plume, and of its temporal variability.

Once calibrated, the airborne sea surface salinity maps provided a sequence of near-synoptic views of the entire Herbert River plume and of portions of the more northerly Tully River plume at intervals of about 3 days. Plume frontal boundaries were clearly visible in the maps near the southern end of Hinchinbrook Island and in the northwest arm of the Hinchinbrook Channel. Salinities were not generally resolved from the air in the narrower southeast arm, but some data acquired there on March 30, when the plume had largely dispersed, was consistent with that obtained in the northwest arm, and along the east coast of the island.

Where corresponding in situ data were available, there was generally good agreement with the location of the frontal zone and with the salinities in the frontal transition region. The Herbert River plume front off Lucinda was sharpest on March 27, at a time when the river discharge was relatively weak, but the weather was calm and tidal currents were neap, so that vertical mixing was likely much reduced. A tongue of more saline water, which emerged inside this frontal zone, was identified in this map and found to have a corresponding signature in CTD profiles crossing the plume. The presence and possible dynamical significance of this feature would likely have been missed without the aid of the airborne data, and its horizontal extent (about 2/3 of the length of Hinchinbrook Island) could not have been readily determined using a surface vessel, even if its presence was known in advance. The combined data set enabled us to precisely determine the zone of influence of the plume in the regional context, under the conditions prevailing during the experiment.

In coastal areas, airborne remote sensing of salinity thus promises to complement, rather than replace, the in situ methods. To the extent that air- and satellite-borne systems are unable to penetrate deeper than a few millimetres or centimetres of the water surface, in situ methods of determining subsurface structure will still be necessary in most plume studies. However, the enhanced spatial and temporal resolution of surface salinity maps derived from remote sensing platforms provide a means to interpolate and even extrapolate in situ data over the plume and ambient waters. Such maps could also be assimilated into, or used to calibrate or validate, mathematical models.

We look forward to employing this technology in a variety of coastal marine settings in the future, and we anticipate that new applications will emerge readily, partic- ularly as the accuracy and precision of the techniques are refined.

Spot measurements of sea surface salinity from space were first attempted using Skylab (Lerner \& Hollinger, 1977), but not until the early 1990s had the technology advanced to the stage where practical imaging satelliteborne instruments could be proposed (Lagerloef et al., 1995). The first satellite-borne soil moisture and sea surface salinity mapping systems are likely to be the European Space Agency's SMOS (Font, Kerr, \& Berger, 2000), with a planned launch in 2006, and the National Aeronautics and Spaced Administration Aquarius, intended for launch at about the same time. Due to antenna size restrictions, satellite instruments are unlikely to have a nominal spatial resolution better than about $50 \mathrm{~km}$. Therefore, while we look forward to the day when global sea surface salinity variations can be mapped from space, the use of airborne platforms will continue to be the only practical approach for mapping salinity in coastal areas in the foreseeable future.

\section{Acknowledgements}

Purchase of the Australian-owned SLFMR was facilitated by an Australian Research Council (ARC) Research Infrastructure and Equipment Fund (RIEF) grant. International support for the grant application, and assistance with technology transfer, came from the US National Oceanic and Atmospheric Administration, owners of the prototype SLFMR, and from the US Naval Research Laboratory, which helped develop it. Dr. M. Goodberlet (ProSensing) built the SLFMR, provided expert advice, and assisted with aircraft installation and flight testing. The GBR campaign was funded by ARC Large Grant A00000536, and additional funding and in-kind support came from Airborne Research Australia (ARA), the Australian Institute of Marine Science, Flinders University, the Great Barrier Reef Marine Park Authority, and the School of Mathematical and Physical Sciences at James Cook University. ARA was established using funding from the Australian Commonwealth's Major National Research Facilities (MNRF) Program. We thank Mr. Cary McLean and Mr. Jeff Warbrick (AIMS), Mr. Rudi Gaissmaier, Mr. Wolfgang Lieff, and Mr. Graham Wilkins (ARA), and Mr. Ray Casey (JCU) for technical assistance and field support. We also thank Cessna 404 pilot, Captain Ian Drennan (ARA), and the Masters and Crews of the RV Lady Basten and RV Titan for expert operational support. Meteorological and hydrological data were provided by the Australian Bureau of Meteorology and the Queensland Department of Natural Resources.

\section{References}

Blume, H. -J. C., \& Kendall, B. M. (1982). Passive microwave measurements of temperature and salinity in coastal zones. IEEE Transactions on Geoscience and Remote Sensing, GE-20(3), 394-404. 
Blume, H. -J. C., Kendall, B. M., \& Fedors, J. C. (1978). Measurement of ocean temperature and salinity via microwave radiometry. BoundaryLayer Meteorology, 13, 295-308.

Bowman, M. J., \& Esaias, W. E. (1978). Oceanic fronts in coastal processes (p. 114). New York: Springer-Verlag.

Burrage, D. M., Goodberlet, M. A., \& Heron, M. L. (2002, Jan.). Simulating passive microwave radiometer designs using SIMULINK. Simulation, 78(1), 36-55.

Burrage, D. M., Heron, M. L., Hacker, J. M., Stieglitz, T. C., Steinberg, C. R., \& Prytz, A. (2002). Evolution and dynamics of tropical river plumes in the Great Barrier Reef: an integrated remote sensing and in situ study. Journal of Geophysical Research (Special issue on Salinity, 107, C12, SRF 17-1 to 17-22, doi:10.1029/2001JC001024).

Dicke, R. H. (1946). The measurement of thermal radiation at microwave frequencies. The Review of Scientific Instruments, 17(7), 268-274.

Droppleman, J. D., \& Mennella, R. A. (1970). An airborne measurement of the salinity variations of the Mississippi River outflow. Journal of Geophysical Research, 75(30), 5909-5913.

Font, J., Kerr, Y., \& Berger, M. (2000). Measuring ocean salinity from space. Backscatter, 11(3), 17-19.

Goodberlet, M. A. (2000a, Feb.15). Australian scanning low-frequency microwave radiometer test and acceptance report. Quadrant Engineering, 37.

Goodberlet, M. A. (2000b, Jan.20). Australian scanning low-frequency microwave radiometer general specifications and data interface description. Quadrant Engineering, 17.

Goodberlet, M. A. (2000c, Jan.18). Australian scanning low-frequency microwave radiometer software manual. Quadrant Engineering, 14.

Goodberlet, M. A., \& Swift, C. T., 1993. A remote sensing system for measuring estuarine and coastal ocean surface salinity. Progress Report \#2 prepared for NOAA under contract 50-DKNA-1-00119 to US Dept. of Commerce, 111 (Quadrant Engineering, Hadley, MA).

Goodberlet, M. A., Swift, C. T., Kiley, K. P., Miller, J. L., \& Zaitzeff, J. B. (1997). Microwave remote sensing of coastal zone salinity. Journal of Coastal Research, 13(2), 363-372.

Hardy, W. N., Gray, K. W., \& Love, A. W. (1974). An S-band radiometer design with high absolute precision. IEEE Transactions on Microwave Theory and Techniques, 382-390 (MTT-22).

Klein, L. A., \& Swift, C. T. (1977). An improved model for the dielectric constant of sea water at microwave frequencies. IEEE Journal of Oceanic Engineering, OE-2(1), 104-111.

Lagerloef, G. S. E., Swift, C. T., \& Le Vine, D. M. (1995). Sea surface salinity: the next remote sensing challenge. Oceanography, 8, 44-50.

Le Vine, D. M., Griffis, A., Swift, C. T., \& Jackson, T. J. (1994). ESTAR: a synthetic aperture microwave radiometer for remote sensing applications. Proc. IEEE 82, vol. 12 (pp. 1787-1798).

Le Vine, D. M., Kao, M., Garvine, R. W., \& Sanders, T. (1998). Remote sensing of ocean salinity: results from the Delaware Coastal Current experiment. Journal of Atmospheric and Oceanic Technology, 15, $1478-1484$.

Lerner, R. M., \& Hollinger, J. P. (1977). Analysis of $1.4 \mathrm{GHz}$ radiometric measurements from Skylab. Remote Sensing of Environment, $6,251-269$.

Miller, J. L. (2000). Airborne remote sensing of salinity. Backscatter, 11(3), $24-27$.

Miller, J. L., Goodberlet, M. A., \& Zaitzeff, J. B. (1998, April 7). Remote sensing of salinity in the coastal zone. EOS, Transactions of $A G U$, 79(14), 3.

Paris, J.F. (1969). Microwave radiometry and its applications to marine meteorology and oceanography (pp. 120-129). Texas: College Station (Texas A\&M Project 286-13 (Ref. 69-1T)).

Prytz, A., Heron, M. L., Burrage, D., \& Goodberlet, M. (2002). Calibration of the scanning low frequency microwave radiometer. Proceedings IEEE/MTS Oceans 2002, 29-31 Oct., Biloxi, USA, Proceedings CDROM.

Sirounian, V. (1968). Effect of temperature, angle of observation, salinity, and thin ice on microwave emission of water. Journal of Geophysical Research, 73, 4481-4486.

Skolnik, M. I. (1970). Radar handbook (p. 66). New York: McGrawHill, ch. 11.

Skou, N. (1989). Microwave radiometer systems: design and analysis (p. 162). Norwood, MA: Artech House.

Stieglitz, T., \& Steinberg, C. R. (2001). AIMS Data Report: remote sensing of sea surface salinity, ground truthing March 2000 (p. 68). Townsville, Australia: Australian Institute of Marine Science.

Swift, C. T. (1980). Passive microwave remote sensing of the ocean-a review. Boundary-Layer Meteorology, 18, 25-54.

Thomann, G. C. (1973). Remote measurement of salinity in an estuarine environment. Remote Sensing of Environment, 2, 249-259.

Ulaby, F. T., Moore, R. K., \& Fung, A. K. (1981). Microwave remote sensing active and passive Vol. I, Microwave remote sensing fundamentals and radiometry (p. 456). Norwood, MA: Artech House.

Wolanski, E., \& Jones, M. (1981). Physical properties of Great Barrier Reef Lagoon waters near Townsville: I. Effects of Burdekin River floods. Australian Journal of Marine and Freshwater Research, 32, 305-319.

Wolanski, E., \& van Senden, D. (1983). Mixing of Burdekin River flood waters in the Great Barrier Reef. Australian Journal of Marine and Freshwater Research, 34, 49-63. 